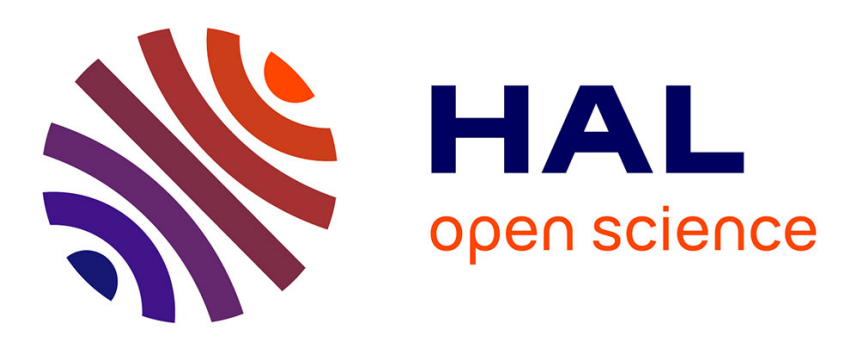

\title{
Aero-Hydro-Elastic Simulation of Semi-Submersible Floating Wind Turbine
}

\author{
Maxime Philippe, Aurélien Babarit, Pierre Ferrant
}

\section{To cite this version:}

Maxime Philippe, Aurélien Babarit, Pierre Ferrant. Aero-Hydro-Elastic Simulation of SemiSubmersible Floating Wind Turbine. Journal of Offshore Mechanics and Arctic Engineering, 2014, 136 (2), 10.1115/1.4025031 . hal-01145190

\section{HAL Id: hal-01145190 \\ https://hal.science/hal-01145190}

Submitted on 2 May 2019

HAL is a multi-disciplinary open access archive for the deposit and dissemination of scientific research documents, whether they are published or not. The documents may come from teaching and research institutions in France or abroad, or from public or private research centers.
L'archive ouverte pluridisciplinaire HAL, est destinée au dépôt et à la diffusion de documents scientifiques de niveau recherche, publiés ou non, émanant des établissements d'enseignement et de recherche français ou étrangers, des laboratoires publics ou privés. 


\title{
Aero-Hydro-Elastic Simulation of a Semi- Submersible Floating Wind Turbine
}

\author{
Maxime Philippe, Aurélien Babarit, Pierre Ferrant \\ LHEEA Lab. (ECN-CNRS), Ecole Centrale Nantes, \\ LUNAM Université, Nantes 44321, France
}

This paper presents an aero-hydro-elastic model of a semi-submersible floating wind tur-bine. A specific attention is drawn to hydrodynamic modeling options and their effect on the dynamic response of the platform. The NREL 5 MW reference wind turbine mounted on the historical concept of semi-submersible platform Dutch tri-floater is considered. A specific hydrodynamic model of loads on a semi-submersible platform is used within the wind turbine design code FAST from NREL. This hydrodynamic model includes nonlinear hydrostatic and Froude-Krylov forces, diffraction/radiation forces obtained from linear potential theory, and Morison forces to take into account viscous effects on the braces and damping plates. The effect of the different hydrodynamic modeling options is investi-gated. As one could have expected, it is found that the effect of viscous drag on braces, and nonlinear Froude-Krylov loads, becomes larger with increasing wave height. Their effect remains of small order. Simulations also are run with directional waves, it is found that wave directionality induces larger transverse motions.

\section{Introduction}

The numerous floating wind turbine concepts that are currently being studied are mostly based on offshore $O \& G$ technology. Among them, semi-submersible platforms are gaining recent industrial attention [1]. For this type of platform, wave loads will be significant due to the large floating area, and could induce relatively large motions of the structure. Therefore, minimizing wave loads action on the structure will be in the center of the conception process [2].

Numerical simulations of floating wind turbine response should be able to model aerodynamic loading and damping, hydrodynamic loading and damping, and structural dynamics. Several numerical models have been developed to combine these effects in a coupled simulation. Some of them resolve the motions in frequency domain [3]; in that case hydrodynamic loads are calculated with linear potential flow theory. In the case of time domain simulations, linear potential theory can also be used to calculate hydrodynamic loads [4]. It allows one to take into account for linear hydrodynamic radiation and linear diffraction loads. This linear approach is valid in the case of small motions regarding to body length. Another approach is to use Morison equation to calculate the hydrodynamic loads [5]. But the Morison equation is only relevant in the case of slender body. A combination of linear potential theory forces and viscous drag forces can be used to model these different effects as done, for instance, by [6,7], where second order potential forces may also be taken into account [8]. The linear hydrodynamic theory is valid only when linearization assumptions are respected. When these hypotheses are not respected it is possible to add some nonlinear formulations for certain loads, such as viscous drag. This combination of linear loads and nonlinear loads is not consistent with the linearization process, but it has been found that it improves the results in practice. This approach is commonly used in offshore O\&G industry, in particular for semi-submersible platforms.

This study aims at evaluating the effect of hydrodynamic modeling options on the results of aero-hydro-elastic simulations

\footnotetext{
${ }^{1}$ Corresponding author
}

of semi-submersible floating wind turbine. A focus has been placed on the effect of viscous drag on braces, and nonlinear Froude-Krylov loads (calculated on instantaneous wetted surface), and on the effect of wave directionality.

FAST design code [9] from National Renewable Energy Laboratory (NREL) is used to model the NREL $5 \mathrm{MW}$ reference wind turbine, which is mounted on the historical concept of semi-submersible platform Dutch Tri-floater [10]. A specific hydrodynamic model of loads on semi-submersible platform has been developed for FAST. It is based on the use of diffraction/radiation theory, Morison loads, and nonlinear hydrostatic and Froude-Krylov loads. This model is used to compute the motions of the system in regular waves, with and without viscous drag, and with and without nonlinear Froude-Krylov loads, in order to assess their effects. These effects are studied with regard to the wave height. Motions of the floating wind turbine in irregular waves are also computed. In particular the effect of a directional wave spectrum, on the system motions and on the power production, is investigated.

\section{Model Development}

Aero-hydro-elastic simulations are run with the FAST design code from NREL [9]. FAST includes a platform load model named HydroDyn [6]; this model has not been used in the present study. A user-defined model for the hydrodynamic loads on the platform has been developed to use hydrodynamic codes from LHEEA Lab. This allows us to model nonlinear Froude-Krylov loads and viscous drag on the braces and heave plates.

Incident Wave Modeling. In this paper, an incident wave is modeled according to linear theory in infinite water depth, as the sum of a large number of Airy waves. Free surface elevation $\eta$ is computed as follows (Eq. (1)):

$\eta(x, y, t)=\sum_{i=1}^{N_{\beta}} \sum_{j=1}^{N_{\omega}} A\left(\omega_{i}, \beta_{i}\right) \sin \left[k_{i}\left(x \sin \beta_{j}+y \sin \beta_{j}\right)-\omega_{i} t+\phi_{i j}\right]$

where $A_{i}^{2}=2 S\left(\omega_{i}, \beta_{i}\right) \delta_{\omega_{i}} \delta_{\beta_{i}}$ with $S(\omega, \beta)$ is the directional wave spectrum, and $\phi_{i j}$ represents the phase uniformly distributed as an independent stochastic variable. 


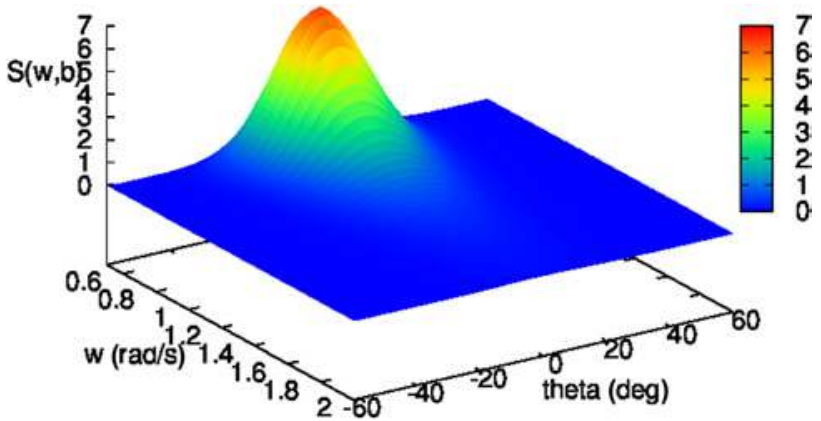

Fig. 1 Directional wave spectrum for $\gamma=1$ (Pierson-Moskowitz) and $s=40$

The directional wave spectrum $S(\omega, \beta)$ is defined as $S(\omega, \beta)=S(\omega) G(\beta)$, where $S(\omega)$ is the frequency wave spectrum, and $G(\beta)$ is the direction spreading function. Several formulations exist for $S(\omega)$ and $G(\beta)$. In this paper, the JONSWAP spectrum is used. $G(\beta)$ is defined classically as defined by [11]

$$
G(\beta)=C_{1}(s) \cos ^{2 s} \frac{\beta-\bar{\beta}}{2} ; \quad \pi \leq \beta-\bar{\beta} \leq \pi
$$

with $\bar{\beta}$ the mean wave direction. $C_{1}(s)$ is a normalization coefficient. A value of $s=10$ represents wind wave, $s=25$ is suitable for small wavelength waves, and $s=75$ is suitable for long waves [12]. Figure 1 shows a directional wave spectrum for $s=40$.

Platform Load Modeling. FAST solves the equation of motion of the wind turbine system in time domain. This equation can be written as

$$
M_{\text {sys }} \ddot{X}=F+F_{\text {ptfm }}
$$

In this equation $F_{\mathrm{ptfm}}$ is the vector of the loads on the platform and $F$ is the vector for other loads. In this study the focus is on the calculation of the $F_{\mathrm{ptfm}}$ vector. Loads on the platform $F_{\mathrm{ptfm}}$ are calculated, according to Eq. (4), as the sum of the following contributions:

- radiation loads $F_{\text {rad }}$

- diffraction loads $F_{\text {dif }}$

- Froude-Krylov loads $F_{\mathrm{FK}}$

- hydrostatic loads $F_{\text {hstc }}$

- a contribution from Morison equation $F_{\text {mori }}$

- mooring loads $F_{\text {anc }}$

Calculations of the different terms is detailed below

$$
F_{\mathrm{ptfm}}=F_{\mathrm{rad}}+F_{\mathrm{dif}}+F_{\mathrm{FK}}+F_{\mathrm{hstc}}+F_{\text {mori }}+F_{\mathrm{anc}}
$$

Radiation Loads. Radiation loads are calculated according to the linear potential flow theory (Eq. (5)). $\mu_{\infty}$ is the added mass matrix, and $K^{\mathrm{rad}}$ is the matrix of the memory terms of the radiation force. These matrices can be calculated with a diffraction/ radiation code, such as WAMIT,

$$
F^{\mathrm{rad}}(t)=-\mu_{\infty} \ddot{X}(t)-\int_{0}^{t} K^{\mathrm{rad}}(t-\tau) \dot{X}(\tau) d \tau
$$

Diffraction Loads. $F_{\text {dif }}$ are also calculated with linear hydrodynamic theory, using diffraction impulse responses $K_{7}$, according to Eq. (6). $\eta_{0}^{\beta_{i}}$ is the wave elevation associated to the incident wave direction $\beta_{\mathrm{i}}$,

$$
F_{\text {dif }}(t)=\sum_{i=1}^{N_{\beta}} \int_{-\infty}^{+\infty} K_{7}\left(t-\tau, \beta_{i}\right) \eta_{0}^{\beta_{i}}(t) d \tau
$$

Froude-Krylov Loads. $F_{F K}$ can be calculated on the mean free surface according to linear theory (Eq. (7)). Alternatively, these loads may also be calculated on the instantaneous wetted surface according to Eq. (8). These loads are named nonlinear Froude-Krylov when they are integrated on the instantaneous wetted surface. Contribution of these loads in the nonlinear behavior of vessels has been studied in [13], and comparisons of numerical simulations and experiments for large amplitude motions of wave energy converters have shown satisfying agreement [14],

$$
\begin{gathered}
F_{\mathrm{FK}}(t)=\sum_{i=1}^{N_{\beta}} \int_{-\infty}^{+\infty} K_{\mathrm{ex}}\left(t-\tau, \beta_{i}\right) \eta_{0}^{\beta_{i}}(t) d \tau \\
F^{\mathrm{FK}}=-\int_{S} p_{d} \vec{N} d S
\end{gathered}
$$

where $p_{d}$ is the dynamic pressure force associated with incident wave potential, such as $p_{d}=-\rho\left(\partial \phi_{i} / \partial t\right) . \phi_{i}$ is the first order potential associated with incident wave, $S$ is the instantaneous wetted surface, and $\vec{N}$ is the generalized normal vector.

Hydrostatic Loads. Hydrostatic loads can also be calculated either on the mean free surface (Eq. (9)) or on the instantaneous wetted surface (Eq. (10)),

$$
F^{\mathrm{hstc}}(t)=-K_{h} X(t)
$$

$K_{h}$ is the hydrostatic stiffness matrix as defined in [4],

$$
F^{\mathrm{hstc}}=-\int_{S} p_{s} \vec{N} d S
$$

$p_{s}$ is the static pressure, such as $p_{s}=p_{0}-\rho g z$.

Morison Loads. Morison loads permit us to take into account some loads which are not modeled in the previous terms, namely drag loads. Morison equation gives the loads on a cylindrical body placed in an oscillatory flow [15]. For a slice of cylinder located in $(X(t), Y(t))$ and for a flow $(U(t), V(t))$ in the plane of the slice, Morison loads can be written as Eq. (11),

$$
\begin{aligned}
\left(\begin{array}{c}
d F_{X} \\
d F_{Y}
\end{array}\right)= & \underbrace{\left.\frac{1}{2} \rho C_{D} \begin{array}{r}
U-\dot{X} \\
V-\dot{Y}
\end{array}\right) \sqrt{(U-\dot{X})^{2}+(V-\dot{Y})^{2}} d L}_{I} \\
& +\underbrace{[\rho\left(1+C_{m}\right) \pi \frac{D^{2}}{4}\left(\begin{array}{c}
\dot{U} \\
\dot{V}
\end{array}\right) \underbrace{-\rho C_{m} \pi \frac{D^{2}}{4}\left(\begin{array}{c}
\ddot{X} \\
\ddot{Y}
\end{array}\right) d L}_{I I I}]}_{I I}
\end{aligned}
$$

In Eq. (11), term 1 represents the drag loads and term 2 represents the inertia loads. $C_{D}$ and $C_{m}$ coefficients can be determined experimentally. To calculate the Morison loads on the floater, the structure is partitioned into elements of cylinder. The total load is integrated along the cylinders composing the structure. Inertia loads are only calculated for the elements of the structure, which are not modeled with potential theory or direct pressure integration. Drag loads are calculated for the small diameter elements.

Mooring Loads. Mooring loads $F_{\text {anc }}$ are calculated with an equivalent linear stiffness matrix and a constant vertical pretension, $F_{\text {anc }}=F_{a, 0}-K_{a} X$. 


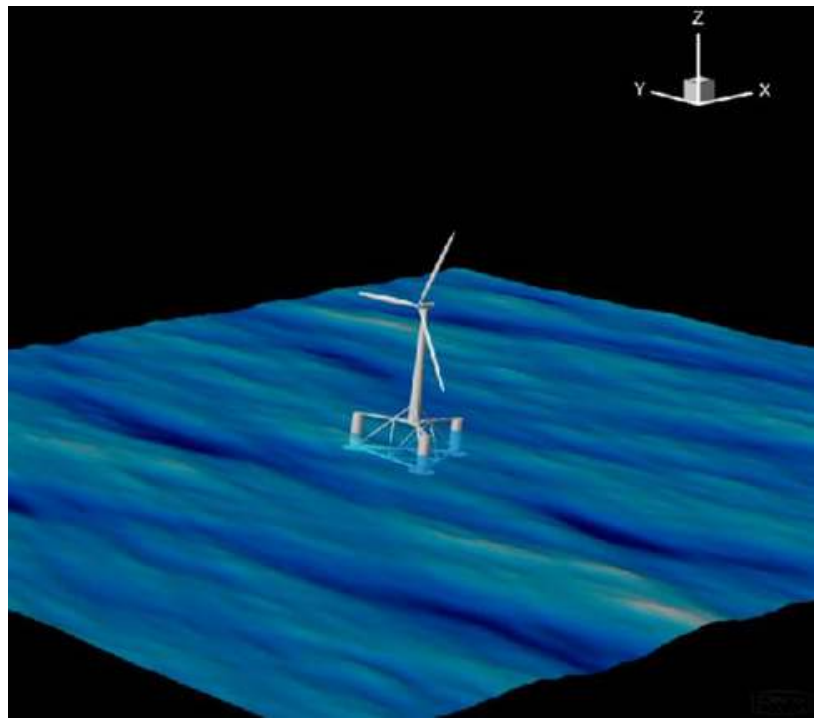

Fig. 2 Simulation of the Dutch tri-floater in irregular directional waves

\section{Model Properties}

Floating Wind Turbine Properties. The floating platform used in this study is the historical concept known as the Dutch

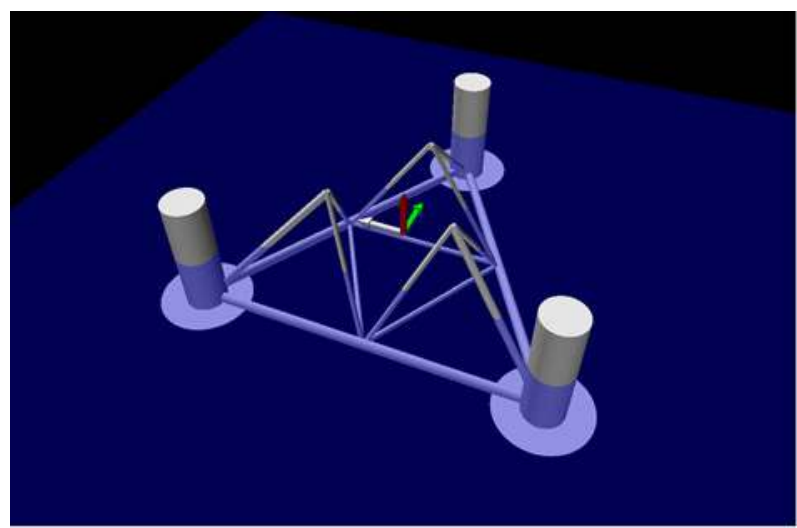

(a)

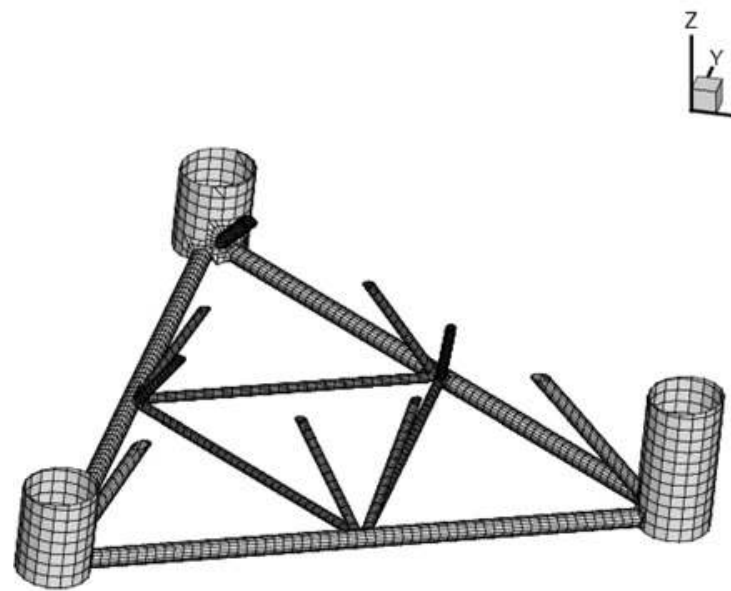

(c)
Table 1 Summary of system properties

\begin{tabular}{lr}
\hline \hline Floater mass & 1148.0 te \\
Ballast mass & 435.2 te \\
Turbine mass & 678.3 te \\
Mooring pretension & 183.5 te \\
System center of mass & $19.0 \mathrm{~m}$ \\
Buoyancy center & $-7.1 \mathrm{~m}$ \\
Displacement & 2545.0 te \\
\hline
\end{tabular}

tri-floater (see Fig. 2). It is a column stabilized platform composed of three columns of $8 \mathrm{~m}$ diameter separated by $68 \mathrm{~m}$. These three columns are connected with braces which also support the wind turbine. Heave plates are placed at the bottom of each column in order to reduce amplitude of motions. Table 1 summarizes some properties of the floater. All properties can be found in [10].

The wind turbine mounted on this platform is the reference $5 \mathrm{MW}$ turbine from NREL [16]. This wind turbine is designed to have a hub height of $90 \mathrm{~m}$. The tower of the turbine has been adapted in order to fit this value and to connect with the Dutch trifloater. The length of the new tower is $62.6 \mathrm{~m}$, the base diameter is $8 \mathrm{~m}$, and the mass is $328 \mathrm{t}$.

Hydrodynamic Loads Calculation. The Dutch tri-floater platform is composed of different parts, three columns, braces, and three heave plates. Each of these parts has different dimensions and therefore should be considered differently for the hydrodynamic load calculation.

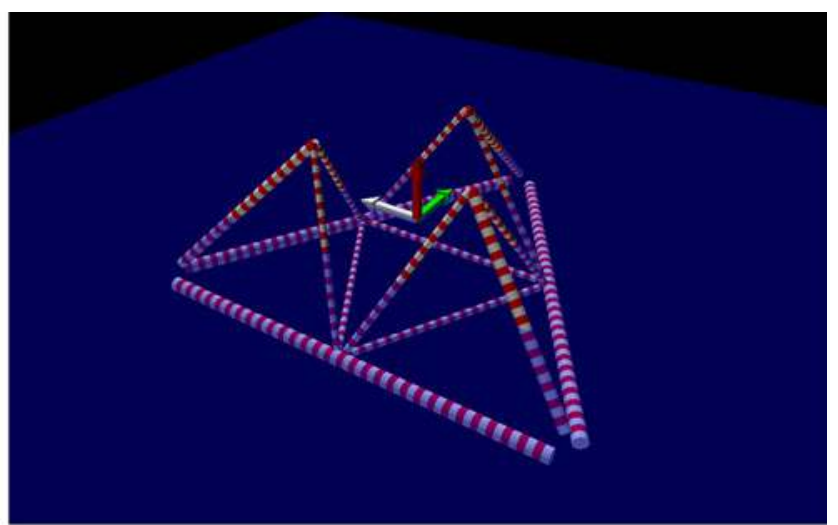

(b)

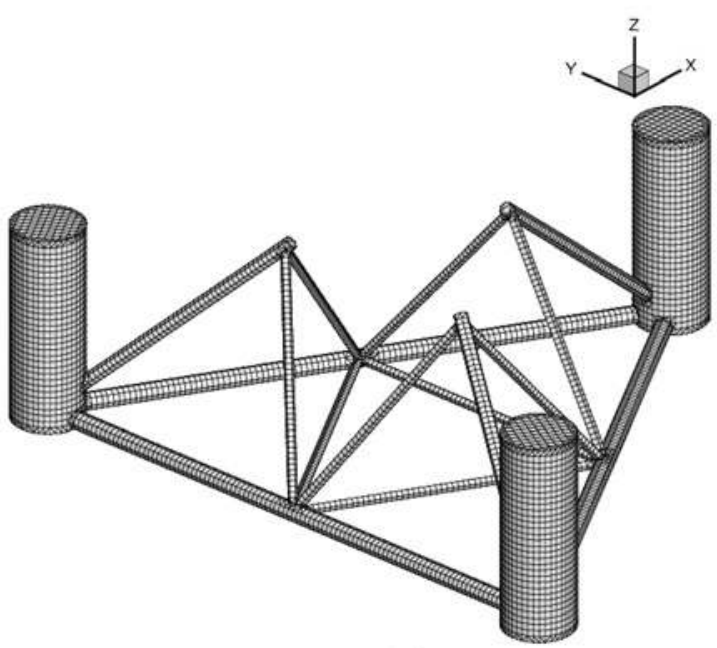

(d)

Fig. 3 (a) View of the platform, (b) mesh of the braces for Morison drag loads calculation, (c) mesh of Dutch tri-floater platform used with Aquaplus for potential flow calculation, and (d) mesh used for nonlinear Froude-Krylov loads calculation 


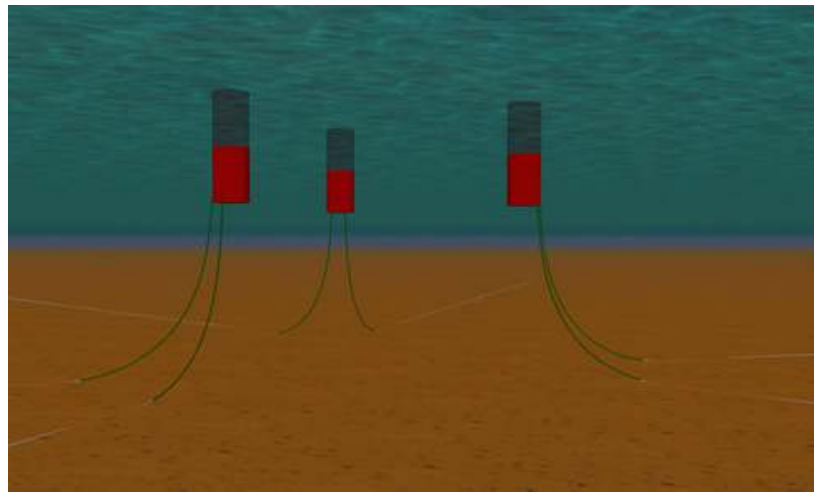

Fig. 4 Picture of the mooring system modeling with OrcaFlex [23]

As the dimension of the three columns is relatively large, linear potential theory is suitable to compute the hydrodynamic loads exerted on it. This theory is used in the present study. For the braces, as the diameters are relatively small, wave damping will be negligible compared to viscous drag. The order of magnitude of the Keulegan-Karpenter number $K_{C}$ is 3-7 for $1 \mathrm{~m}$ waves. Therefore, Morison drag will be applied to the braces. Inertial loads can be calculated with linear potential theory for the braces. They are not taken into account in the Morison calculation, but they are taken into account in the potential flow calculation.

Figure 3(c) represents the meshes used for the calculation of linear hydrodynamic properties (added mass, wave damping, and excitation force). This calculation has been performed with Aquaplus [17]; the floater has been considered in steady state position (position due to a constant wind and without waves). The mesh used for the calculation of nonlinear Froude-Krylov loads is represented in Fig. 3(d). Figure 3(b) shows the mesh used for the calculation of Morison viscous drag on the braces. A viscous drag coefficient $C_{d}$ of 0.7 was chosen.

Heave plates of the platform have a diameter of $18 \mathrm{~m}$. Such heave plates have been used by $O \& G$ industry, in particular for spar platforms. They are thought to reduce the platform motions. These plates have two simultaneous effects, they create viscous damping due to flow separation at edges, they increase the heave added mass; it may shift the natural periods out of wave range period.

In the case of a semi-submersible platform, draft is reduced, and plates are located near the free surface (with comparison to a spar). In that case the plates also increase wave excitation forces [18]. This effect is balanced by the increase of damping. The main effect remains the shift of natural frequency. Ishiara et al. [19] studied the influence of heave plates in the case of semi-submersible floating wind turbine through water tank test. They found that these plates increase heave natural period and reduce motions at extreme sea states.

In this paper the effect of the plates on the platform motions is modeled with an in-line (in plate axis) Morison force. Drag and inertia coefficients $C_{d}$ and $C_{m}$ have to be determined for the geometry of the plates. According to Bearman et al. [20], drag coefficient for a rectangular planar plate is $7.8 K_{C}^{1 / 3}$ (with $K_{C}$ the
Keulegan Carpenter number). It gives an order of 6-10 for our geometry; a $C_{d}$ value of 8 has been chosen. Regarding the added mass coefficient $C_{m}$, the added mass of an oscillating cylindrical plate is approximately equal to the mass of the equivalent hemisphere [21]. In the case of a plate and a cylinder, the contribution of cylinder is deducted and added mass becomes Eq. (12) [22],

$$
\begin{aligned}
m_{a}= & \frac{1}{3} \rho D_{d}^{3}-\left[\frac{\pi \rho}{8} D_{c}^{2}\left(D_{d}-\sqrt{D_{d}^{2}-D_{c}^{2}}\right)\right. \\
& \left.+\frac{\pi \rho}{24}\left(D_{d}-\sqrt{D_{d}^{2}-D_{c}^{2}}\right)^{2}\left(2 D_{d}+\sqrt{D_{d}^{2}-D_{c}^{2}}\right)\right]
\end{aligned}
$$

with $D_{c}$ the diameter of the cylinder and $D_{d}$ the diameter of the plate. Equation (12) has been used to calculate the added mass value used in the Morison equation.

Mooring Loads Modeling. Mooring loads are modeled as a linear restoring force and a constant vertical load. The stiffness matrix is calculated with OrcaFlex [23]. The same mooring system as the one proposed in [10] has been used. This is a six lines mooring system, each line is composed of $190 \mathrm{~m}$ of cable and $225 \mathrm{~m}$ of chain (chain length is slightly reduced by comparison to [10]). Figure 4 shows a picture of mooring system modeling. By perturbing each platform degree of freedom (DOF), the stiffness matrix has been calculated, and the following representation for the mooring system has been obtained,

$$
\begin{gathered}
F_{a}=F_{a, 0}-K_{a} X \\
F_{a, 0}=\left(\begin{array}{c}
0 \\
0 \\
-1.8 \cdot 10^{5} \\
0 \\
0 \\
0
\end{array}\right)
\end{gathered}
$$

$$
K_{a}=\left(\begin{array}{cccccc}
1.6 \cdot 10^{5} & 0 & 0 & 0 & 1.9 \cdot 10^{6} & 0 \\
0 & 1.6 \cdot 10^{5} & 0 & -1.9 \cdot 10^{6} & 0 & 0 \\
0 & 0 & 1.5 \cdot 10^{5} & 0 & 0 & 0 \\
0 & -1.9 \cdot 10^{6} & 0 & 1.1 \cdot 10^{8} & 0 & 0 \\
1.9 \cdot 10^{6} & 0 & 0 & 0 & 1.1 \cdot 10^{8} & 0 \\
0 & 0 & 0 & 0 & 0 & 1.7 \cdot 10^{8}
\end{array}\right)
$$

\section{Results}

Properties of the Four Models Compared. In this paper the results of the four following platform load models are compared:

- M1 is the most complete model. Radiation and diffraction loads are calculated with linear theory. Hydrostatic and Froude-Krylov loads are calculated on instantaneous wetted surface. Drag loads of the Morison equation are also calculated on the braces.

Table 2 Properties of the four hydrodynamic load models (Lin: linear, NL: nonlinear)

\begin{tabular}{lccccc}
\hline \hline & Radiation & Diffraction & Froude- Krylov & Hydrostatic & Morison drag on braces \\
\hline M1 & Lin & Lin & NL & NL & $C_{d}=0.7$ \\
M2 & Lin & Lin & Lin & Lin & $C_{d}=0.7$ \\
M3 & Lin & Lin & NL & NL & no \\
M4 & Lin & Lin & Lin & Lin & no \\
\hline \hline
\end{tabular}


Table 3 Simulation cases specifications

\begin{tabular}{lcc}
\hline \hline & Description & Wave conditions \\
\hline E1 & Time-series-generated "effective RAOs" & Regular Airy $-A=1 \mathrm{~m} \omega=0.05,0.015, \ldots, 2.05 \mathrm{rad} / \mathrm{s}$ \\
E2_1 & Periodic time series - Effect of wave amplitude & Regular Airy $-A=0.1 \mathrm{~m}, \ldots, 5 \mathrm{~m}-\omega=0.6 \mathrm{rad} / \mathrm{s}$ \\
E2_2 & Periodic time series - Effect of wave amplitude & Regular Airy $-A=0.1 \mathrm{~m}, \ldots, 5 \mathrm{~m}-\omega=1.0 \mathrm{rad} / \mathrm{s}$ \\
E3_1 & Time series statistics - Effect of wave directionality & M1, M2, M3, M4 \\
E3_2 & Time series statistics - Effect of wave directionality & Irregular directional Airy $-\gamma=1-\mathrm{s}=40-H_{s}=6 \mathrm{~m}-T_{p}=10 \mathrm{~s}$ \\
\hline \hline
\end{tabular}

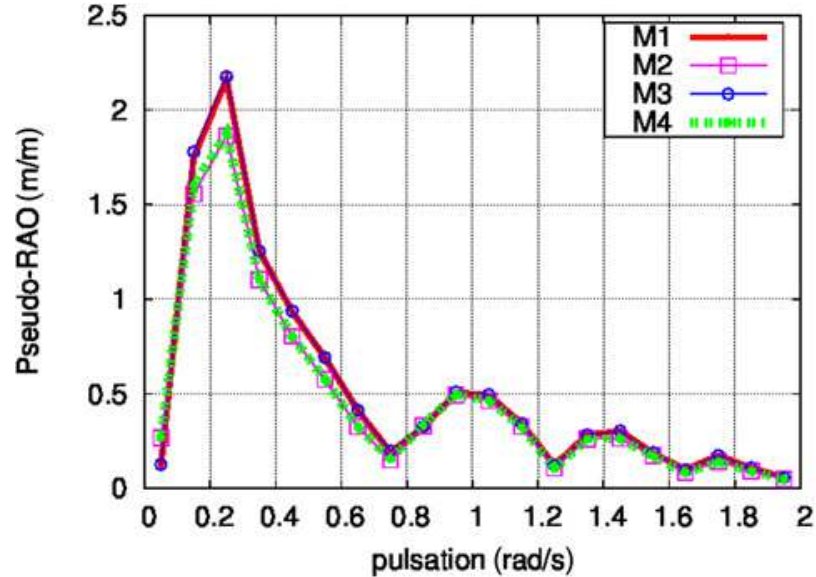

(a) surge

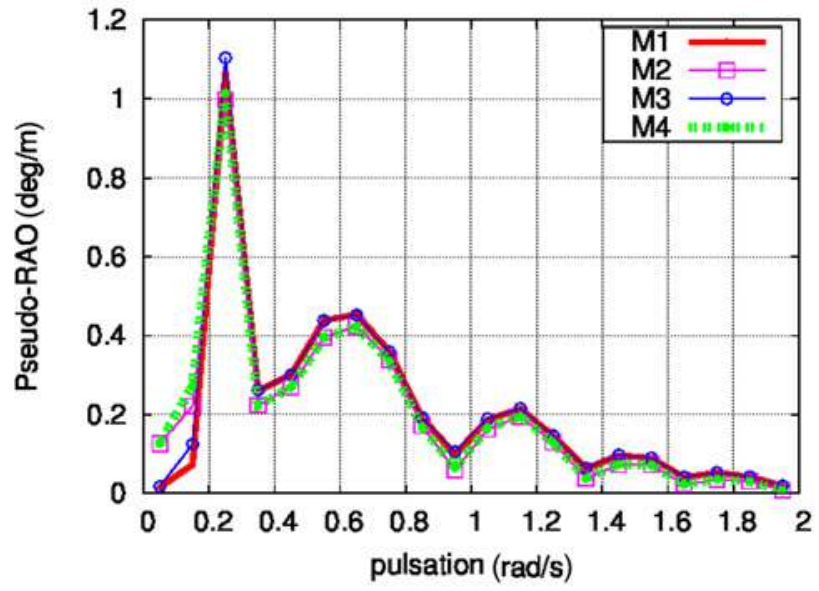

(c) pitch

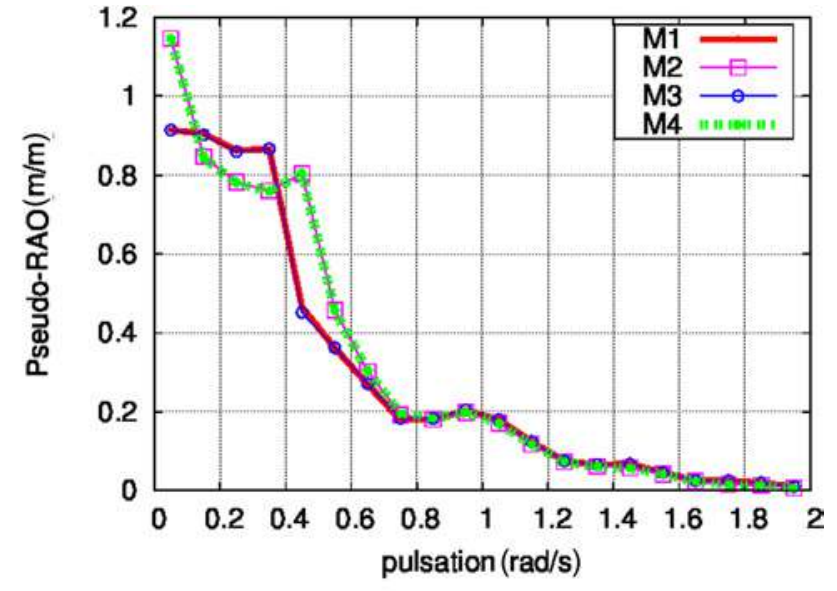

(b) heave

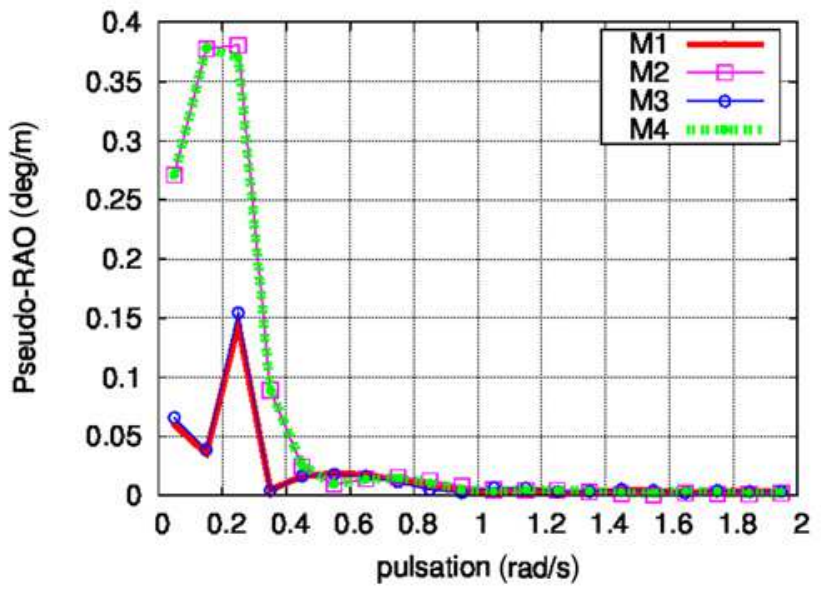

(d) yaw

Fig. 5 Effective RAOs of the platform surge, heave, pitch, and yaw motions

- M2 is the same as M1 except that hydrostatic and FroudeKrylov loads are calculated with linear theory.

- M3 is the same as M1 except that Morison loads on braces are not taken into account.

- M4 is the simplest model. Radiation, diffraction, FroudeKrylov, and hydrostatic loads are calculated according linear theory, and viscous drag on braces is not calculated. The only nonlinear hydrodynamic terms come from the damping plate modeling.

Properties of these four models are summarized in Table 2.

Simulation Cases Description. Time domain simulations with the four models M1, M2, M3, and M4 have been run. For all simulations presented here, the water depth is considered as infinite; wind and wave are supposed to be aligned; wind speed is constant at $11.2 \mathrm{~m} / \mathrm{s}$; the wind turbine model is a FAST fully flexible model. Three different types of simulation have been run.
The first simulations, E1, are time series of 2000 s. Wave amplitude is $1 \mathrm{~m}$ and wave frequency varies from 0.05 to $2.05 \mathrm{rad} / \mathrm{s}$; waves are regular. The system reaches a permanent state after a transient state. "Effective Response Amplitude Operators" (RAO) are deduced from the permanent oscillations around a mean position. As the model includes nonlinearities, these "effective RAOs" are not classical RAO in the sense of linear seakeeping theory. The results obtained with the four platform loads models M1, M2, M3, and M4 are compared.

The second kind of simulations E2 are also ran with regular waves. Two wave frequency $0.6 \mathrm{rad} / \mathrm{s}$ and $1 \mathrm{rad} / \mathrm{s}$ have been chosen, and varied the wave amplitude from $0.1 \mathrm{~m}$ to $5 \mathrm{~m}$, to identify the influence of wave height. Again the results for the four platform models are compared.

Finally, irregular waves simulations have been run with platform model M1. Incident waves characteristics are $H_{s}=6 \mathrm{~m}$, $T_{p}=10 \mathrm{~s}$ with a Pierson Moskovitz spectrum. The results of unidirectional waves are compared with the results for directional 


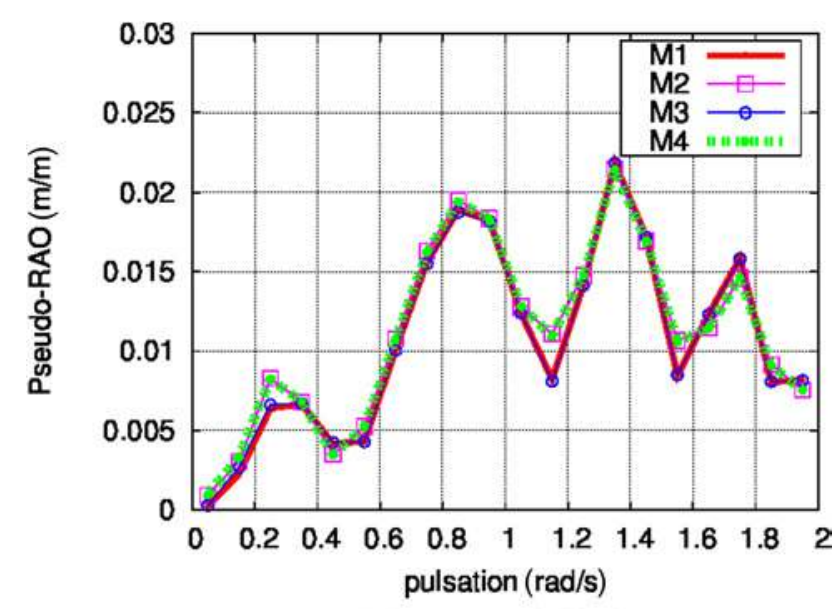

(a) tower top deflection

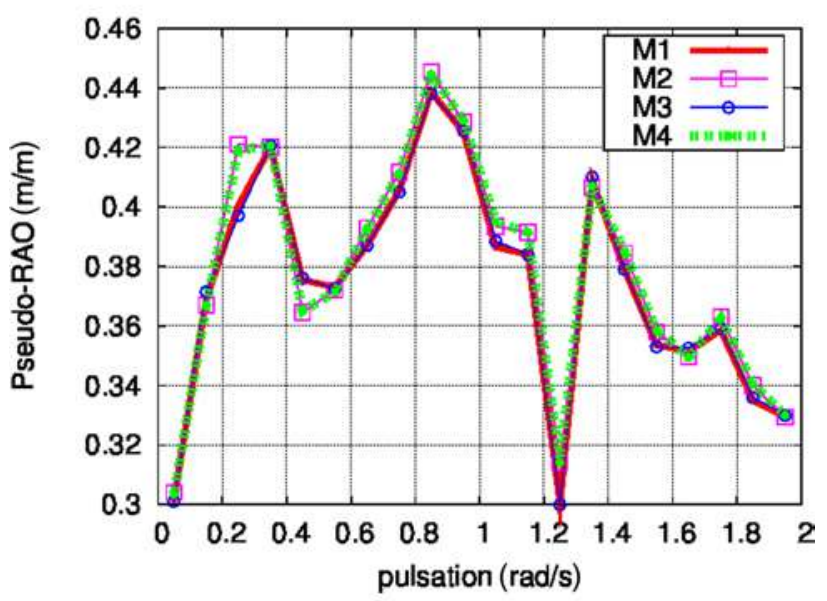

(b) out of plane blade tip deflection

Fig. 6 Effective RAOs of the tower top deflection and out of plane blade tip deflection

waves with a spreading parameter $s=40$. The characteristics of these simulations are summarized in Table 3 as the effect of nonlinear Froude-Krylov loads and viscous drag, and effective response amplitude operators.

The results of the E1 simulations are shown in Figs. 5 and 6. Figure 5 shows the RAOs of the platform surge, heave, pitch, and yaw motions. For the surge motion, the results of the fourmodels are in good agreement, except around the resonant response around $0.2 \mathrm{rad} / \mathrm{s}$. Around $0.2 \mathrm{rad} / \mathrm{s}$, nonlinear Froude-Krylov loads slightly increase the response, and the difference is not large. For pitch motion, the differences between models are also small. Models M1 and M3 (with nonlinear Froude-Krylov) give a slightly larger motion around $0.6 \mathrm{rad} / \mathrm{s}$. For yaw motion the effect of nonlinear Froude-Krylov is noticeable for low frequency. But the order of magnitude of the yaw remains small in all simulations, The permanent state for transverse motions is not perfectly reached, so it is difficult to conclude on this effect.

Figure 6 represents the RAOs of tower top deflection and out of plane tip deflection. As the difference between hydrodynamic models were not large for platform motion, the differences in wind turbine motion are also small.

Wave Height Sensitivity. For $1 \mathrm{~m}$ amplitude incident wave, results between the four models were not very different. For $0.6 \mathrm{rad} / \mathrm{s}$ and $1 \mathrm{rad} / \mathrm{s}$ waves, the influence of wave height has been studied. Figure 7 represents the results for pitch and tower base pitching moment TwrBsMyt, in the case of the $1 \mathrm{rad} / \mathrm{s}$ incident

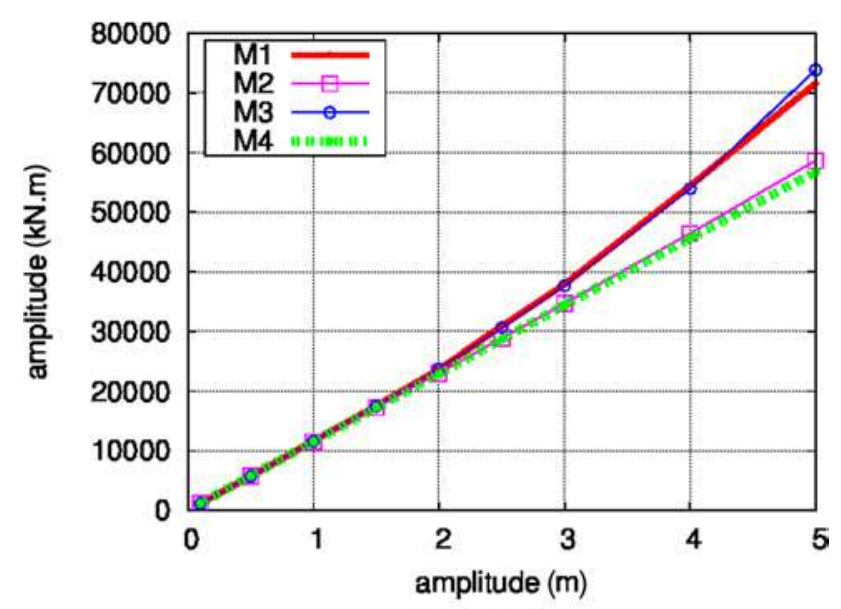

(a) TwrBsMyt

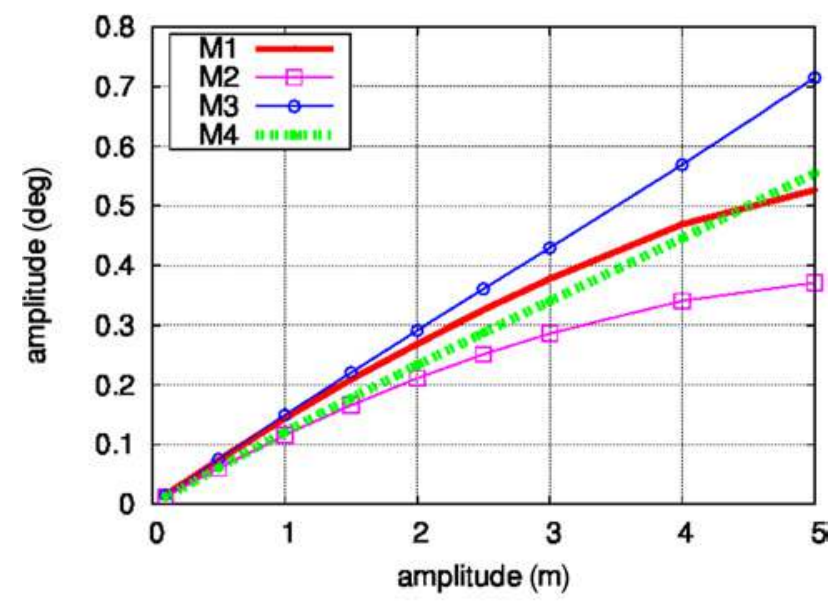

(b) pitch

Fig. 7 Amplitude of pitch motion and tower base pitching moment around a mean value with regards to wave amplitude for an incident wave of pulsation $\omega=1 \mathrm{rad} \mathrm{s}^{-1}$

wave. The differences between the models become more significant when wave height increases, but orders of magnitude remain the same.

For $0.6 \mathrm{rad} / \mathrm{s}$ incident wave, results are shown in Fig. 8. For model M4, the simulations were not stable for amplitude greater than $3 \mathrm{~m}$, that is why there are no results plotted. Same conclusions are obtained as for $1 \mathrm{rad} / \mathrm{s}$ waves, the differences between models become larger with increasing wave height, but orders of magnitude remain the same.

Influence of Wave Directionality. Results of the simulations with irregular unidirectional waves (E3-1) and simulations with irregular directional waves have been compared. Simulations runtime is $600 \mathrm{~s}$. On these $600 \mathrm{~s}$ the 300 first are not taken into account for statistics in order to avoid transient computational effects. It remains $300 \mathrm{~s}$ for the statistics. Wave elevation for these $300 \mathrm{~s}$ is shown in Fig. 9 for the two simulations. One should note the duration of simulation is short $(5 \mathrm{~min})$ for the statistics, and the $300 \mathrm{~s}$ of simulation before statistics may be not enough to ensure a permanent state, in particular for the transverse motions. Nevertheless, the trends observed seem significant.

An increase of transverse motions (sway, roll, and yaw) of the platform is observed, as one could have expected. Comparison of yaw motions has been plotted in Fig. 10(b). This 


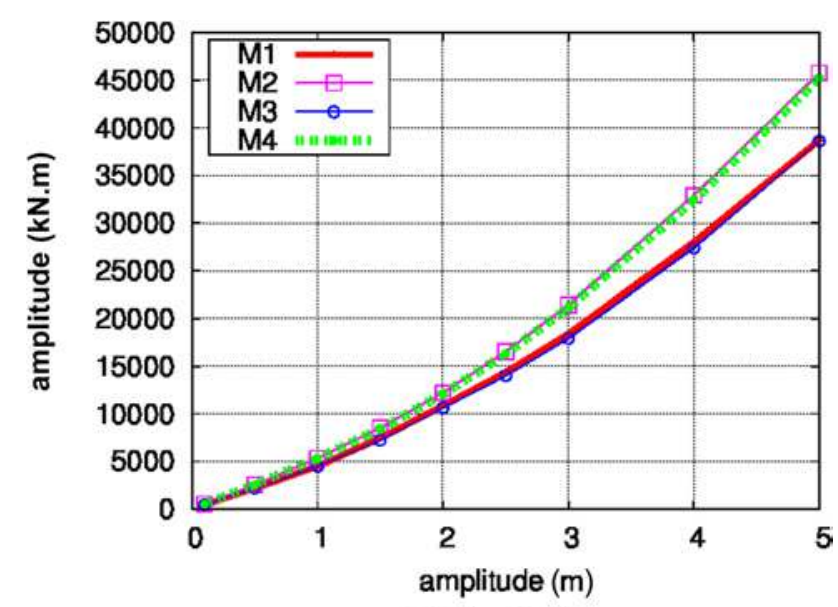

(a) TwrBsMyt

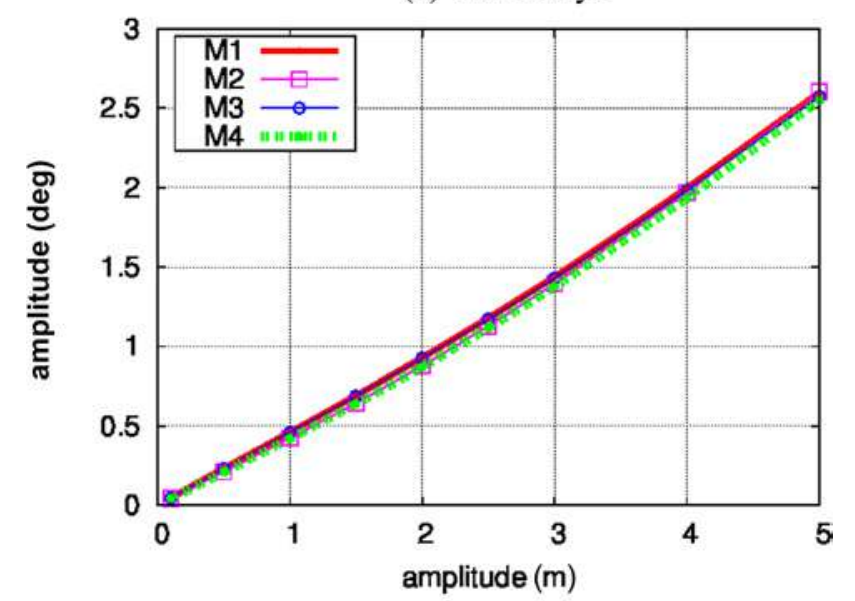

(b) pitch

Fig. 8 Amplitude of pitch motion and tower base pitching moment around a mean value with regards to wave amplitude for an incident wave of pulsation $\omega=0.6 \mathrm{rad} \mathrm{s}^{-1}$

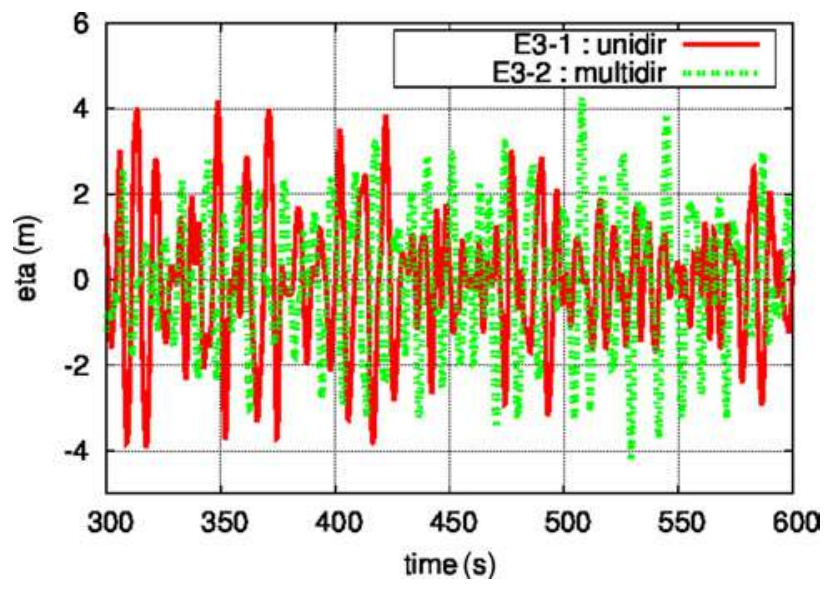

Fig. 9 Wave elevation for irregular directional waves and unidirectional waves

increase of yaw motion could lead to an increase of structural loads, which should be taken into account for design. Regarding axial motions (surge, heave, pitch), a small reduction of amplitude is observed (see Fig. 10(a) for the representation of pitch

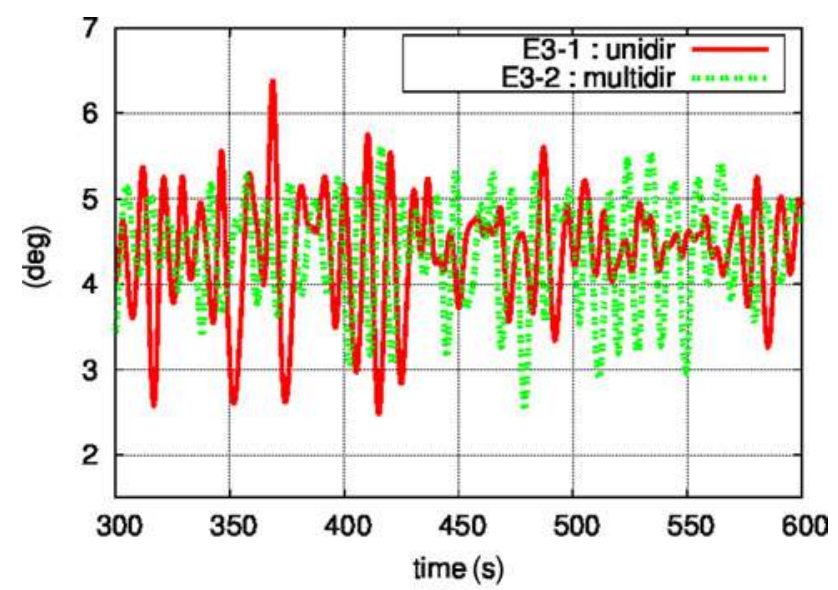

(a) pitch

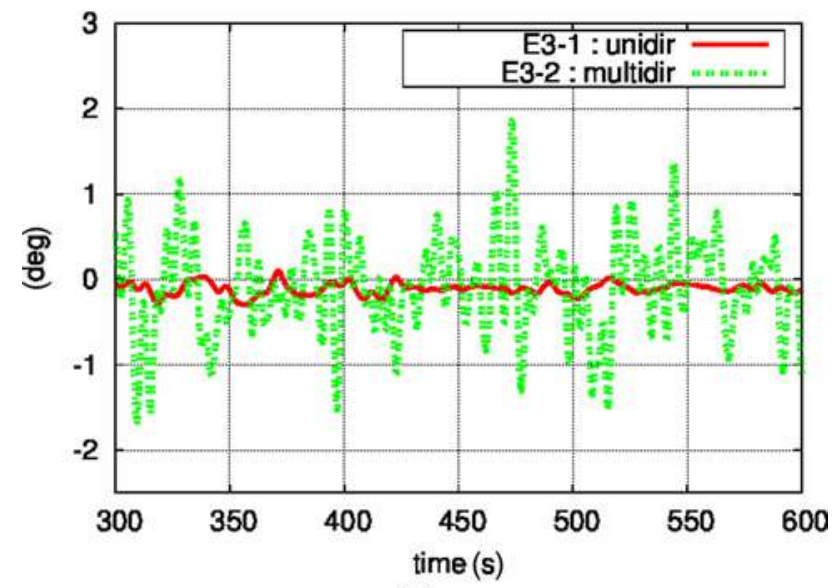

(b) yaw

Fig. 10 Comparison of pitch and yaw motions in irregular directional waves and unidirectional waves

Table 4 Statistics for generated power, tower deflection, blade deflection, surge, pitch, and yaw, in the case of irregular directional waves and unidirectional waves

\begin{tabular}{|c|c|c|c|c|c|c|}
\hline & \multicolumn{2}{|c|}{ GenPwr (kW) } & \multicolumn{2}{|c|}{ TTDspFA (m) } & \multicolumn{2}{|c|}{ OOPDelf1 (m) } \\
\hline & Mean & Std. Dev. & Mean & Std. Dev. & Mean & Std. Dev. \\
\hline \multirow{4}{*}{$\begin{array}{l}\text { E3-1: Unidir } \\
\text { E3-2: Multidir }\end{array}$} & 4678.9 & 281.9 & 0.10 & 0.02 & 5.49 & 0.27 \\
\hline & 4678.3 & 281.0 & 0.10 & 0.02 & 5.49 & 0.28 \\
\hline & \multicolumn{2}{|c|}{ Surge (m) } & \multicolumn{2}{|c|}{ Pitch (deg) } & \multicolumn{2}{|c|}{ Yaw (deg) } \\
\hline & Mean & Std. Dev. & Mean & Std. Dev. & Mean & Std. Dev. \\
\hline E3-1: Unidir & 3.44 & 1.04 & 4.39 & 0.64 & -0.11 & 0.07 \\
\hline E3-2: Multidir & 3.46 & 1.01 & 4.38 & 0.61 & -0.10 & 0.55 \\
\hline
\end{tabular}

motion). Statistics for surge, pitch, and yaw motions are presented in Table 4.

Concerning the generated power, wave directionality seems to have little influence on mean generated power and standard deviation. Table 4 presents these statistics. Figure 11 shows the tower base moment. These loads are calculated in a coordinate system fixed to tower base. We observe a strong increase of the moment in roll in the case of directional waves. Tower base moment in roll remains smaller than the moment in pitch. 


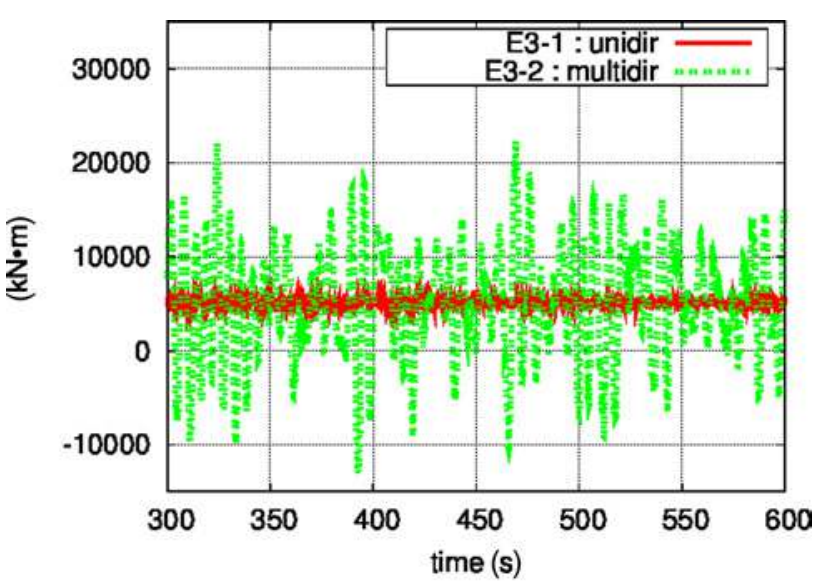

(a) TwrBsMxt

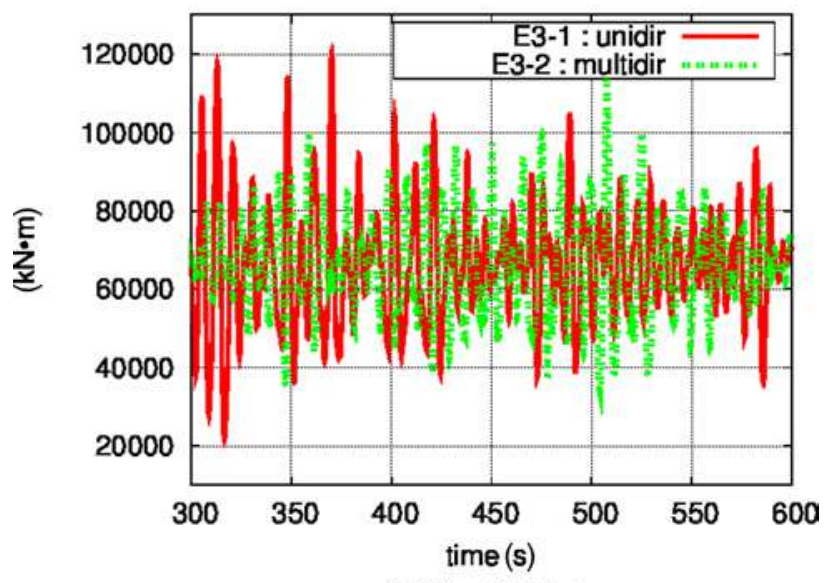

(b) TwrBsMyt

Fig. 11 Comparison of tower base moment for the case of irregular unidirectional and directional waves

\section{Conclusion}

In this paper the results of time domain simulations of a semisubmersible floating wind turbine have been compared for four different models of hydrodynamic loads on the floater. Then the effect of wave directionality on the system in irregular waves has been studied.

The four platform load models gave similar results for $1 \mathrm{~m}$ amplitude waves. Viscous drag on the braces and nonlinear Froude-Krylov loads have little influence. With increasing wave height, the differences become larger. In some cases, nonlinear Froude-Krylov loads bring out larger motions, however order of magnitude remains the same. Water tank tests would be interesting to confirm these results, and to verify that the nonlinearity added to hydrodynamic model permit us to obtain numerical results closer to experiment. Regarding the hydroydnamic model, this study could be completed by addition of a second order wave loads model, to quantify their effect on the system dynamics.

Concerning the effect of wave directionality, an increase of transverse motions, sway, roll, yaw, and a small reduction of axial, surge, pitch and yaw motions, have been observed. Increase of transverse motions induces an increase of transverses loads on the wind turbines. No significant influence on the generated power has been observed.

In the present study extreme waves have not been considered. In the case of extreme conditions, floater dimensions become small regarding to wave amplitude. The use of the Morison equation could be considered to calculate the hydrodynamic loads on the entire floater. Further investigations are needed to quantify the influence of hydrodynamic modeling of semi-submersible floating wind turbine in the case of extreme waves.

\section{Acknowledgment}

The authors would like to acknowledge ADEME (the French environment agency) and Région Pays de la Loire for funding the $\mathrm{Ph} . \mathrm{D}$ program in which this study is included.

\section{References}

[1] Roddier, D., Peiffer, A., Aubault, A., and Weinstein, J., 2011. "A Generic 5 MW Windfloat for Numerical Tool Validation and Comparison Against Generic Spar," International Conference on Ocean, Offshore and Arctic Engineering.

[2] Henderson, A., and Witcher, D., 2010, "Floating Offshore Wind Energy-A Review of the Current Status and an Assessment of the Prospects," Wind Eng., 34(1), pp. 1-16.

[3] Wayman, E., Sclavounos, P., Butterfield, S., Jonkman, J., and Musial, W., 2006, "Coupled Dynamic Modeling of Floating Wind Turbine Systems," 2006 Offshore Technology Conference, 1-4 May 2006, Houston, TX.

[4] Jonkman, J., 2007, "Dynamics Modelling and Load Analysis of an Offshore Floating Wind Turbine," Ph.D. thesis, University of Colorado, Boulder.

[5] Whithee, J., 2004, "Fully Coupled Dynamic Analysis of a Floating Wind Turbine System," Ph.D. thesis, Department of Ocean Engineering, MIT.

[6] Jonkman, J., 2009, "Dynamics of Offshore Floating Wind Turbines - Model Development and Verification," Wind Energy, 12, pp. 459-492.

[7] Cermelli, C., Roddier, D., and Aubault, A., 2009, "Windfloat: A Floating Foundation for Offshore Wind Turbines Part Ii: Hydrodynamic Analysis," International Conference on Ocean, Offshore and Arctic Engineering.

[8] Ormberg, H., Passano, E., and Luxcey, N., 2011, "Global Analysis of a Floating Wind Turbine Using an Aero-Hydro-Elastic Model: Part 1-Code Development and Case Study," International Conference on Ocean, Offshore and Arctic Engineering.

[9] Jonkman, J., and Buhl, M., 2005, FAST User Guide, National Renewable Energy Laboratory.

[10] ECN, MARIN, L. t. W. T. T. M., 2002. Study to Feasibility of and Boundary Conditions for Floating Offshore Wind Turbines, Technical Report.

[11] Longuet-Higgins, M. S., Cartwright, D. E., and Smith, N. D., 1961. "Observations of the Directional Spectrum of Sea Waves Using the Motions of a Floating Buoy," Proc. Ocean Wave Spectrum, pp. 111-122.

[12] Goda, Y., 2010, Random Seas and Design of Maritime Structures, Vol. 33, World Scientific, Singapore.

[13] Kat, J. D., and Paulling, J., 1989, "The Simulation of Ship Motions and Capsizing in Severe Sea State," Trans. SNMAE, 97, pp. 139-168.

[14] Gilloteaux, J., Babarit, A., Ducrozet, G., Durand, M., and Clément, A., 2007. "A Non-Linear Potential Model to Predict Large-Amplitude-Motions: Application to the Searev Wave Energy Converter," International Conference on Ocean, Offshore and Arctic Engineering.

[15] Morison, J., O'Brien, M., Johnson, J., and Schaaf, S., 1950, "The Force Exerted By Surface Waves on Piles," Petrol. Trans., 189, pp. 149-154.

[16] Jonkman, J., Butterfield, S., Musial, W., and Scott, G., 2009, "Definition of a 5-MW Reference Wind Turbine for Offshore System Development," Technical Report NREL/TP-500-39060, National Renewable Energy Laboratory.

[17] Delhommeau, G., 1993. "Seakeeping Codes Aquadyn and Aquaplus," 19th WEGEMT School Numerical Simulation of Hydrodynamics: Ships and Offshore Structures.

[18] Cermelli, C. A., and Roddier, D. G., 2005, "Experimental and Numerical Investigation of the Stabilizing Effects of a Water-Entrapment Plate on a Deepwater Minimal Floating Platform," International Conference on Ocean, Offshore and Arctic Engineering.

[19] Ishihara, T., Waris, M., and Sukegawa, H., 2009, "A Study on Influence of Heave Plate on Dynamic Response of Floating Offshore Wind Turbine System," in Proceedings of the 3rd European Offshore Wind Conference and Exhibition, Stockholm, Sweden, pp. 14-16.

[20] Bearman, P., Downie, M., Graham, J., and Obasaju, E., 1985, "Forces on Cylinders in Viscous Oscillatory Flow at Low Keulegan-Carpenter Numbers," J. Fluid Mech., 154(1), pp. 337-356.

[21] Sarpkaya, T., and Isaacson, M., 1981, Mechanics of Wave Forces on Offshore Structures, Van Nostrand Reinhold, New York.

[22] Tao, L., and Cai, S., 2004, "Heave Motion Suppression of a sapr With a Heave Plate," Ocean Eng., 31, pp. 669-692.

[23] Orcina, 2010, OrcaFlex User Manual v 9.4a. Orcina Ltd. 